\section{P156 ADHERENCE TO VITAMIN D PROPHYLAXIS IN INFANT UNDER 1 YEARS OF AGE. A RE-AUDIT OF VITAMIN D SUPPLEMENTATION, COMPLIANCE AND EDUCATION IN SLIGO UNIVERSITY HOSPITAL}

Alessandra Biagini*, Ghia Harrison, Rolf Knapp, Samy A Allawendi, Rohininath Tummaluru. Sligo University Hospital, Sligo, Ireland

10.1136/archdischild-2019-epa.511

Background Vitamin D deficiency in children causes a failure of osteoid to calcify with deficient bone growth and clinical features of rickets. Vitamin D is produced by ultraviolet irradiation of inactive and avoidance of sunlight or poor oral intake in infants exclusively breastfed may contribute to the development of this pathology.

Objective To study the compliance of vitamin D supplementation in children from birth to 12 months of age and to educate and create awareness among healthcare professionals and people regarding vitamin $\mathrm{D}$ supplementation.

Standards of care The HSE policy supports vitamin D supplementation for all infants from birth to 12 months of age: all infants, whether breastfed or formula fed, should be given a daily supplement of $5 \mu \mathrm{g}$ (or 200 I.U) Vitamin D. This should be provided by a supplement containing vitamin D exclusively.

Methodology In this re-audit we collected data prospectively using an anonymous structured collection form of all the children from birth to 1 year of age that attended our OPD and day cases clinics from august 2018 to January 2019. We then compared these recent results with 3 previous outcomes on a similar audit done in 2010 by our Team. The outcomes confronted are: children that received the vitamin D supplement, appropriateness and compliance to the therapy and education given to the families.

Results Majority of children $80 \%$ (40) had received Vitamin D and among those the $61.2 \%$ (30) were receiving the correct dose. In the previous audit $75 \%$ had received Vitamin D and among these 59\% were receiving it correctly.

In this study the $85 \%$ of the parents were educated by healthcare providers, with a prevalence of Public Health Nurses $54,5 \%$ (31), 28\% (16) by paediatricians and only $17.5 \%$ (10) by general practitioners, while in the previous results the $95 \%$ were educated by Health Care Providers.

Doctors advised to administer Vitamin D during the last visit to the clinic in only the $34.8 \%$ (16) of cases.

Conclusions The increased compliance of Vitamin D administration reflects a higher awareness of the importance of Vitamin D supplementation but the $41 \%$ of the population is still receiving a sub-optimal dose.

Recommendation Healthcare providers should give more information to the mothers and especially they should encourage Vitamin D administration at every visit.

\section{P157 ROLE OF BLOOD CULTURE IN CHILDHOOD COMMUNITY ACQUIRED PNEUMONIA}

\footnotetext{
1,2Muhammad Shoaib Iqbal*, 'Muhammad Waqar Khan, 'Bazlin Ramly, ${ }^{1}$ Pankaj Agrawal, ${ }^{1}$ Asim Khan. 'Letterkenny University Hospital, Letterkenny, Ireland; ${ }^{2}$ Princess Alexandra Hospital, Harlow, UK
}

10.1136/archdischild-2019-epa.512

Background Childhood community acquired pneumonia (CAP) is one of the main reasons for admissions in
Pediatrics department. British thoracic society classifies CAP as mild to moderate and severe CAP. Doing blood Cultures routinely in all the in patients with mild to moderate CAP is not recommended although in severe CAP this can vary.

Objectives To establish if we are following BTS guidelines for mild to moderate community acquired pneumonia regarding Blood culture in children admitted as in-patients to the Paediatric Ward in Letterkenny University Hospital

Methods Criteria selection

Children more than one year of age

Mild to moderate community acquired pneumonia as per BTS guidelines.

Population/Sample Identification

Convenience sampling was used. Data was collected from the Medical Records of children who had been discharged from the Paediatric Ward during the period $1^{\text {st }}$ Dec 2016 to $28^{\text {th }}$ Feb. 2017. Data Collection Sources

Data was collected from the medical record.

Data Abstraction Questionnaire

Data was collected using a short questionnaire.

Data Type

Data was collected on the following areas:

Blood Culture done or not

Method of Analyzing Data

Data was analyzed by the auditor using Microsoft Excel Results

- Total number of charts: 49

- Charts excluded: 18

- Charts included in audit: 31

- Blood cultures done in 15 out of 31 patients which is $48.3 \%$

Conclusion There is poor compliance as per BTS guidelines regarding Blood Culture in patients with mild to moderate community acquired pneumonia

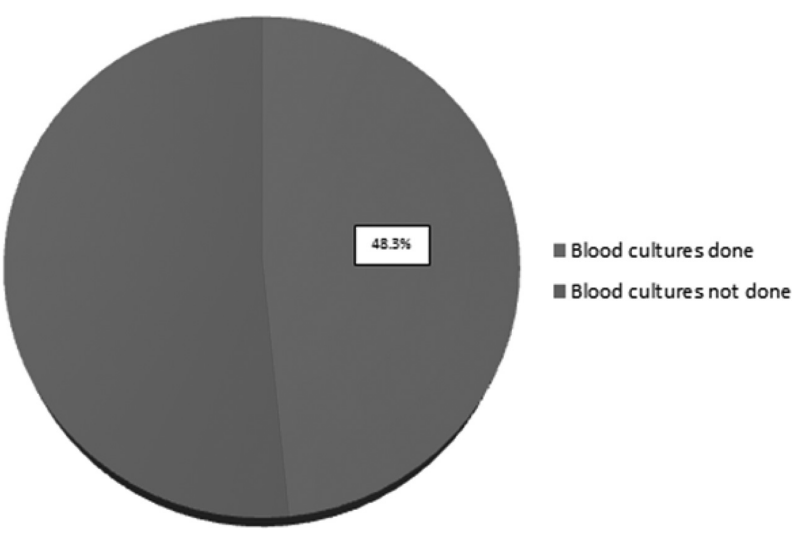

Abstract P157 Figure 1

\section{Recommendations}

- British Thoracic society guidelines should be followed properly managing patients with childhood community acquired pneumonia.

- Un-necessary Blood Cultures should not be done routinely in mild to moderate community acquired pneumonia

- There should be regular teaching sessions on recent guidelines to keep updated all doctors working in Paediatric unit in Letterkenny General Hospital 